\title{
A case study in the valuation of a database
}

Received (in revised form): 15th January, 2007

\begin{abstract}
Kelvin King
heads his own firm, Valuation Consulting. He spent his early career with the British Government's Share Valuation Division (SVD), which is responsible for all of the private company, business, intellectual property, and intangible asset valuation requirements of government. He left the government after 17 years to establish a Valuation Unit for a large accountancy practice and, before the founding of Valuation Consulting, was the MD of a specialist valuation company within a major international Swiss bank. He has undertaken corporate finance work for most of his working life. As well as founding the Society of Share and Business Valuers in the UK he is a contributor to journals, television and radio. He is a contributor to books and his book Valuation and Exploitation of Intellectual Property and Intangible Assets was published by EMIS Professional Publishing. He has been a Law Society UK Expert Witness in the area of intellectual property and intangible asset valuation for many years, is a founding expert of Lord Woolf's Expert Witness Institute, and a member of the Licensing Executive Society, Chartered Institute of Patent Agents (Associate) and the International Association of Consultants, Valuers and Analysts.
\end{abstract}

Keywords database, valuation, intangible assets, IPR

\begin{abstract}
Intellectual capital is recognised as the most important asset of many of the world's largest and most powerful companies; it is the foundation for the market dominance and profitability of leading corporations. The role of intangible assets in business is insufficiently understood and there are major categories that are marketingrelated (trademarks, brands, trade names, trade dress, internet domain names, newspaper mastheads, non-compete agreements, etc) and customer-related, which are those utilised in the development procurement, management and maintenance of a company's customers (customer lists, order or production backlog, customer contracts and related relationships, non-contractual customer relationships, etc). Assets such as a database are viewed by many from a financial background as simply a cost, whereas in truth this asset may well be the highest generator of worth and hence the most valuable within the business. If you do not know the cost and value of your intellectual capital, how can you manage it? The following case study in the valuation of a database will help readers to understand that such assets are capable of robust valuation using widely accepted traditional methodologies.

Journal of Database Marketing \& Customer Strategy Management (2007) 14, 110-119.

doi:10.1057/palgrave.dbm.3250041
\end{abstract}

Kelvin King

Valuation Consulting

90 Chancery Lane,

London WC2A 1EU, UK

Tel: +442073384830

Fax: +442074035556

e-mail: kelvin.king@atisreal.

co.uk

Website: www.valuation-

consulting.co.uk

\section{GENERAL INTRODUCTION}

The valuation scenario discussed below is a typical example of the valuation of a database. The context of the valuation is presented, the information considered in forming a valuation opinion is listed and the basis of valuation and the technique that was used is discussed.

The name of the company and individuals involved in the case study has been invented. Although we endeavoured to use names currently not in use by a company, it is always possible that there may be perceived similarities and we ask reader to disregard any unintended associations.

The names of companies in the market and comparability sections and facts about them are in the public domain.

The formation of a valuation opinion is by and large an art, not a science. A 
valuation opinion is a judgment made on the basis of available facts about the subject asset and the market in which it is exploited. Although formation of an opinion employs some formal techniques and methods, and the proper presentation of the opinion requires some rhetorical skill, valuation cannot be taught using recipes like cooking. Only experience that has been tested in a commercial or legal setting is a reliable guide. We hope that this case study will share some of our experience with you.

Before embarking upon any valuation, it is essential to establish the correct concept of the value, for example fair market value, open market value, fair value, owner value or investment value. Each concept has its own set of rules, often derived from a combination of case law, statute and/or regulatory practice. It is not within the scope of these case studies to discuss these differences in detail, but it is important to note that the concept of value used in forming a valuation opinion must be appropriate to the purpose of the valuation.

When a valuation is to be submitted to a tax authority, tax open market value will almost always be used. The definition of tax open market value is similar worldwide, but will differ in some details and features according to relevant case law and precedent for the subject tax jurisdiction(s). Although those features and details must be attended to carefully, often, in practice, the broad similarities provide adequate guidance.

Similarly, a valuer preparing a valuation that is to be used in financial statements should consult relevant accounting standards and regulations, as advised by auditors if possible, when choosing a concept of value.

\section{INTANGIBLE ASSETS}

There are many kinds of intangible assets, such as trade marks, patents, copyright, software, databases, trade secrets, know-how, registered designs, domain names, brands and others.
Intangible assets are often narrowly defined for specific legal, accounting or taxation purposes, and for a fiscal or tax-led valuation the appropriate definition must be used. In the current context, it is not useful to provide an exhaustive list of these definitions.

In order to be a candidate for valuation, an intangible asset should have the following characteristics:

- It should be subject to specific identification and recognisable description. Because of the breadth and variety of the class of assets, there is no formal system of measurement as in, say, real estate, but one must be able to capture and identify the asset in a sufficiently precise way to allow one to distinguish it.

- It should be subject to the right of private ownership, and the private ownership should be transferable. This does not mean that the asset must be sold, merely that it be capable of transfer. Also, the asset need not necessarily be subject to separate and independent transfer.

- It should have been created or have come into existence at an identifiable time or as the result of an identifiable event and should be typically subject to maintenance. Although not typically a good basis for valuation for most situations, it is usually important to understand the costs involved in the creation and maintenance of the asset under study.

- The property should usually be subject to legal existence protection and/or confidentialities. Examples: an owner must be able to petition the courts for relief from damages to the property due to the actions of another party; an owner must be able to seek protection for the property from theft by another party. As with other legally protected property, the owner will typically have some responsibilities, such as responsibility for damage caused by the asset, or, the asset may be subject to taxation. An example 
of confidentialities would be technical know-how.

- There should be tangible evidence or manifestation of the existence of the asset. For example, a disk, a contract, a listing, a licence, a registration document or a set of financial statements will suffice.

When identifying and describing an asset, it is important to consider its economic life, commercial life and legal life, and its relationship to other assets required to exploit it.

\section{THE VALUATION OF INTANGIBLE ASSETS}

\section{Methodologies of valuation}

There is consensus among valuers that there are three main valuation approaches when valuing intangible assets:

- Cost approach

- Income approach

- Market approach.

\section{Cost approach}

Cost-based methodologies assume that the value of the asset is related to the costs incurred in developing or redeveloping it. While cost is not the same thing as value, it is an acknowledged benchmark for certain types of assets, typically software and workforces.

The starting point when using the cost approach is to obtain an estimate of the cost to produce or reproduce a new replica of the Intellectual Property Rights (IPR).

Many authorities believe that the cost approach is generally the least applicable approach in the appraisal of marketing intangible assets and that, in many instances, the cost approach will underestimate the value.

Overestimation is possible, for example, if software projects get out of control, costs rise, and no functional software are produced. The cost approach may also be less applicable when the asset is old or unique.
Although there are many disadvantages to using the cost approach, it is sometimes the only method for which any data can be found or which will suit the purpose of the valuation. Typically, it is typically often used for software and databases.

\section{Income approach}

In this approach, the value of the IPR is estimated as the present value of the future economic income attributable to the ownership of the asset over its expected remaining useful life.

This approach involves ascertaining the likely future income streams that would accrue to the owner of the subject asset and discounting these back to the date of valuation to reflect the time value of money and the risks associated with each income stream - to find the net present value of the income streams.

Another approach is to take a figure for annual sustainable earnings and, with reference to the market and experience, capitalise this to reach a value.

Assistance in this approach is the relief from royalty, excess profit and gross profit differential methods of calculating the cash flows.

\section{Market approach}

In this approach, assets and transactions relevant to the valuation date involving assets that are similar to the subject asset are used as Guidelines to estimate how the market might value the subject asset.

If relevant data are available, this must be considered. In the presence of good data, the market approach is one of the most direct and systematic approaches to valuation, but it is frequently the case that relevant data may not be readily available.

It is of immense assistance in ascertaining appropriate royalty rates.

\section{Selecting an approach}

In both the UK and the US, most authorities believe that there are several 
factors to consider when selecting an approach, and we borrow their framework here:

- Quantity and quality of data. Data must be present as a basis for a valuation opinion. The type, quality and quantity of data always shape and may limit the valuer's choice of valuation approach. The maturity of the market may dictate what market data will be available. The maturity of the subject asset may influence what type of financial data are available about it.

- Access to available data. In valuations for litigation support or dispute resolution or other contentious or controversial purposes, there may be restricted access to data or specific instruction about how it may be treated. Careful consideration must be given not only to the data available, but also to their usability.

- Supply of relevant transactional data. In industries having a large quantity of available transaction data, market approaches are favoured. The market cannot be ignored when it places a value on assets similar to the subject asset.

- Type and nature of the subject asset. Some industries have rules of thumb or conventions that indicate the value of more or less standard assets. Industry conditions in which the subject intangible is expected to operate should always be acknowledged.

- The particular bundle of rights represented in the subject intangible asset. Economic and legal rights, as well as any special characteristics of ownership interests, must be examined separately. These may impact the choice of valuation approach and technique.

- Statutory, judicial, contractual and administrative requirements and considerations. The valuer should be aware of any specific statutory requirements, administrative guidance or judicial precedents that have a bearing on the valuation due to its purpose or due to the asset itself. Note in our cases below how these considerations shape assumptions about the concept of value.

- Informational needs of the particular audience for the valuation opinion. The level of sophistication and disclosure required for a valuation opinion is very sensitively dependent on the audience for the opinion. A valuation for a shareholder dispute requires a different level of disclosure to a valuation to be used in raising finance. In the former, the valuer's independence may facilitate resolution and minimal detail is made available in order to minimise potential argument. In the latter, explanatory detail is required by potential investors.

- Purpose and objective of the appraisal. For example, a valuation in litigation concerning damages has a backwardlooking orientation and may well place emphasis on costs involved in creation of the asset. Such an approach would not be called for in a valuation used to raise finance for the same asset, if wellfounded forecasts were available.

- Compliance with professional standards.

- Professional judgment and technical expertise. As mentioned in the Introduction, the most reliable guide to the choice of an approach is the experience that comes from having valuation judgment tested by the scrutiny of a wide variety of authorities.

\section{General techniques}

\section{Rules of thumb}

A generally accepted rule of thumb for splitting the expected profits from the exploitation of an intangible asset is that the owner of the asset should get 20-33.3 per cent of the operating profits that the licensee is expected to earn from commercialisation of products that use the licensed property. 
Relief from royalty

This approach hypothesises the royalty that would need to be paid by the user of the IPR, to the owner of the IPR, if the IPR were not owned internally. This royalty rate is often derived from the market and applied to expected revenues from the exploitation of the asset.

The projected royalty stream is taxed, if applicable, and discounted at an appropriate rate of return to produce the value of the rights to use the asset. The rate of return will need to reflect the risk/return relationship implicit in the investment in the asset.

In summary, when using the relief from royalty method, in addition to the royalty rate it is important to consider the

- remaining useful life of the asset;

- remaining life of IPR protection;

— tax rate; and

— discount rate.

\section{Standard caveats}

A valuation opinion is sensitive to the assumed scope of the valuation, and it is applicable for only a narrow and well-defined purpose. These assumptions and the limits of interpretation are included in a set of caveats accompanying the valuation opinion. These are important to consider when reading valuations as the caveats often contain key assumptions that can have technical or modelling implications.

We now set out below a synopsis of a typical report. For ease of use, we have numbered the paragraphs for crossreferencing purposes.

\section{VALUATION OF A DATABASE}

\section{Introduction}

1.1 We were asked by Weight Limited ('Weight'/'the Company') to provide a fair market valuation of the customer database owned by the Company as on 31st December, 2004 (their financial year end).

1.2 The purpose of the valuation was to advise the Board of Weight in the context of business and general strategic plans and decisions and also for financial accounting purposes.

1.3 Weight produces a comprehensive database of musical CDs produced in the UK.

1.4 In the section Nature of Business below, we give more detail on both the Company and the database.

\section{Basis of valuation}

1.5 We adopted fair market value as our basis of valuation. This basis of valuation means the price at which an asset might reasonably be expected to change hands between a willing buyer and a willing seller when the former is not under any compulsion to buy and the latter is not under any compulsion to sell, both parties having reasonable knowledge of relevant facts.

1.6 In addition, Court decisions frequently state that the hypothetical buyer and seller are assumed to be able, as well as willing, to trade and to be well informed about the property and the market for such property.

1.7 This is an objective basis of valuation, which entails a depersonalised approach. This means that we will not necessarily endow the hypothetical purchaser and vendor with the actual characteristics of any parties.

1.8 Fair market value considers the exchange of cash or cash equivalents.

1.9 Such a basis of value may or may not equate to the price achieved in an actual sale. In particular, we took no account of any special purchaser, who may have been prepared to pay a different price for reasons such as 
strength of negotiating position, synergistic or other benefits.

1.10 Subject to the remainder of the report, we were of the opinion that the database was worth £3.25 million as at 31st December, 2004.

\section{INFORMATION, PROCEDURES AND CAVEATS}

\section{Information}

2.1 We had access to the following information supplied by Weight:

- The audited accounts for Weight for the year ended 31st December, 2003, which contained the comparative figures for the year ended 31st December, 2002.

- A copy of Weight's budget figures for the year ended 31st December, 2004.

- A management forecast for Weight for the financial years ended 31st December, 2005, 2006, 2007 and 2008.

- A presentation prepared by the management of Weight for staff headed '2005 Budget Summary.'

- A further presentation prepared by the management of Weight headed 'Planning for 2005.'

\section{Procedures}

2.2 First of all, we ensured that we had adjusted all the financial data listed above to make sure that the figures we used related only to income derived from the database.

2.3 We analysed conditions in, and the economic outlook for, Weight and analysed general market data, including economic and sector forces that may have affect the value of the database.

2.4 We also held discussions with the Managing Director of Weight with whom we have exchanged e-mails.
During these discussions and through the e-mails, we were comprehensively informed of the past history of Weight and its future prospects, including detailed background to their future projections and the underlying assumptions.

2.5 In addition, we gathered and analysed financial data for publicly traded or private companies engaged in the same or similar lines of business to develop appropriate valuation comparisons to apply to the database as part of the Market Approach.

\section{Caveats}

2.6 The following are to be borne in mind in considering our opinion of value:

- We did not perform any work in the nature of an audit on any of the information that was made available to us.

- Our opinion was for the express purpose outlined at paragraph 1.2 above and could not be relied upon for any other purpose whatsoever.

- Insofar as our opinion was based on the forecasts provided to us, we reviewed their compilation to enable us to confirm that they were prepared broadly following the stated underlying assumptions. However, these assumptions were the sole responsibility of Weight and we will accept no responsibility for the ultimate accuracy and realisation of the forecasts. Furthermore, it should be noted that there will usually be differences between forecast and actual results, because events and circumstances frequently do not occur as expected, and these differences may be material.

- The valuation of databases is not an exact science, and others could have had a different view in this regard. 


\section{NATURE OF BUSINESS}

3.1 Weight is a 100 per cent owned subsidiary of Weight Inc., a corporation based in the United States of America.

3.2 As well as the Database, Weight also produced a musical encyclopaedia. All revenues, expenses, etc for this product were excluded for the purposes of this exercise, as they do not relate to the Database.

3.3 Weight is an internet-based company. Their Database of music is very broad in range and scope and is constantly updated for new and rare items. Weight adopted a system whereby the various music experts employed by them select the albums to be put on the Database, the main consideration being whether an album was likely to sell.

3.4 The Database contains details about albums, which could be used by web surfers to help them determine whether or not they wish to buy an album over the internet. Typically, the Database has the following information about an album:

- a brief description of the music;

- details about the artist, composer, orchestra etc.

- details of the record label;

- a picture of the album cover;

- a few seconds of the sound clip from the album.

3.5 As noted above, it is the responsibility of the various experts in their own musical field to decide which albums would appear on the Database and what information should be included. There were 6 people dedicated to the creation of the Database.

3.6 In addition to the one for music, Weight is also developing a Database for films etc on DVD.

3.7 It should be noted that, for copyright reasons, it has been necessary for
Weight to acquire a 'hard copy' of every album and DVD that appears on their Database. At present, product acquisition makes up 5 per cent of Weight's total expenditure. In the current year, one of the key objectives of the company is that 75 per cent of the products be acquired for free through deals with the various record labels.

3.8 Weight was also responsible for the development of a similar music Database for France. This project has now been halted however to enable Weight to concentrate on the UK Database.

3.9 Companies such as Amazon then use the Database in exchange for a licence fee. Licences are sold under contracts that state an agreed payment for the use of the Database, plus additional payments due dependent on how many 'hits' the Database has from the general public.

3.10 In future years, the Company sees the following as market opportunities:

- etailers and traditional bricks-andmortar stores;

- interactive TV; and

- wireless devices, for example, mobile phones.

\section{FINANCIAL INFORMATION}

4.1 The results for Weight for the three years to 31st December, 2004 are set out for completeness below. As with most new and innovative companies without a mature client list, the historic results are of little use in valuing the database:

\begin{tabular}{|c|c|c|c|}
\hline & $\begin{array}{l}2002 \\
\text { Actual } \\
£^{\prime} 000\end{array}$ & $\begin{array}{l}2003 \\
\text { Actual } \\
£^{\prime} 000\end{array}$ & $\begin{array}{l}2004 \\
\text { Budget } \\
£^{\prime} 000\end{array}$ \\
\hline $\begin{array}{l}\text { Total } \\
\text { revenue }\end{array}$ & 187 & 867 & 1,772 \\
\hline $\begin{array}{l}\text { Expenses } \\
\text { Operating } \\
\text { profit/(loss) }\end{array}$ & $\begin{array}{r}853 \\
(666)\end{array}$ & $\begin{array}{l}1,651 \\
(784)\end{array}$ & $\begin{array}{r}1,452 \\
320\end{array}$ \\
\hline
\end{tabular}


4.2 We noted two years of heavy losses in the years 31st December, 2002 and 31st December 2003 but also noted that in the year ended 31st December, 2004 the budget for Weight was to move into profit.

4.3 We outline below a summary of the forecasts relating solely to the database for the four-year period to 31 st December, 2008.

\begin{tabular}{|c|c|c|c|c|}
\hline & $\begin{array}{l}2005 \\
£^{\prime} 000\end{array}$ & $\begin{array}{l}2006 \\
£^{\prime} 000\end{array}$ & $\begin{array}{l}2007 \\
£^{\prime} 000\end{array}$ & $\begin{array}{l}2008 \\
£^{\prime} 000\end{array}$ \\
\hline Total revenue & 1,298 & 1,634 & 1,903 & 2,172 \\
\hline Expenses & 884 & 1,010 & 1,152 & 1,251 \\
\hline Operating profit & 414 & 624 & 751 & 921 \\
\hline
\end{tabular}

4.4 We noted that the company is forecasting a decline in turnover in 2005. We understand that this is due to Weight concentrating on its core business in the UK.

4.5 We also noticed, however, that despite Weight forecasting a drop in turnover, profits were set to increase. This is because, like many successful internet companies, Weight's costs in the early years were essentially very high. This cost was substantially funded by its US parent company. It is, however, clear now that the company had control over its expenses, which have also declined markedly.

\section{VALUATION APPROACH}

5.1 The database had only just started to make profits for the company, but profits are forecast to increase in the future. In these circumstances, the accepted methodology for valuing the asset is via Discounted Cash flow ('DCF') methodology (however, see our comments regarding Cost to Create in paragraph 5.5 below). As such, the value of the forecast cash flows to a given horizon were discounted back to a value at the valuation date taking account of the time value of money and risk.

5.2 We then added a terminal value being the value today of the cash flows after the horizon and into perpetuity (again discounted to reflect time and risk) to give a total value for these cash flows.

5.3 We valued on a debt free basis.

5.4 We assumed a growth into perpetuity of 5 per cent, which is 2.5 per cent above the UK Government's longterm inflation forecast and did not seem unreasonable to us in view of the strength of the sector in which Weight operates.

5.5 We then cross-checked this methodology by two methods. The first was by applying a multiple to the prospective 2008 earnings when the profits of the company can be expected to have stabilised and, secondly, by means of Cost to Create methodology (see methodologies of valuation above).

5.6 For our cash flows, we used the operating profits set out in paragraph 5.3 above. In addition, we pushed the forecasts on by a further year using a growth in the operating profit of 5 per cent to give us a steady-state year.

5.7 We assumed that the previous tax losses will be fully utilised by the end of 2006 and that the company would pay corporation tax at the normal rates from then onwards.

\section{DISCOUNT RATE}

6.1 We adopted the Capital Asset Pricing Model ('CAPM') to arrive at an appropriate discount rate. This can be stated simply as follows:

$$
\mathrm{Ce}=\mathrm{R}_{\mathrm{f}}+\mathrm{B}(\mathrm{Re})
$$

where $\mathrm{Ce}$ is the cost of equity; Rf the risk free rate of return from the market; $B$ the beta; Re the excess 
return to equity from the market over the risk-free rate.

Each of these parameters can be quantified as follows:

1 The risk free rate of return. The best available approximation to this was the yield on 5-15-year Government Bonds in December 2004 (Source: Bloomberg) at approximately 4.75 per cent.

2 The beta. The beta is a measure of the stocks' sensitivity to market movements. The best method of obtaining the beta for an as yet unquoted entity is to use the beta of companies in a similar field as the database. We considered that the most appropriate beta for Weight was 1.0 (Source: London Business School Risk Measurement Survey), being the figure showing in December 2004 for the Media \& Photography Sector of the FTSE - Actuaries Indices.

3 The equity premium. Historically, the consensus view is that the post-tax equity premium has historically always been in the region of 6-8 per cent. Recent research has, however, shown that more recently this has dropped to between 3 and 4 per cent. We adopted 4 per cent.

4 Calculation of the cost of equity. Given the above assumptions, the cost of equity

(Ce) can be calculated thus:

$\mathrm{Ce}=\mathrm{Rf}+\mathrm{B}(\mathrm{Re})$

$\mathrm{Ce}=4.75$ per cent $+1.0(4.0)$ per cent $\mathrm{Ce}=8.75$ per cent

6.2 We, therefore, used an equity discount rate of 8.75 per cent as the first stage in considering the valuation.

6.3 Such a discount rate was not considered appropriate for the valuation of the database. The following points of difference are among those that needed to be considered in arriving at an appropriate discount rate to apply to the database:
- The database does not have a history of profitability.

- CAPM utilises data derived from transactions in quoted stock ('CAPM stock') that has historically paid dividends and can be expected to do so in the future.

- CAPM stock usually has considerable tangible asset backing.

- CAPM stock usually has full access to the capital markets.

- CAPM stock is usually comprised of very substantial businesses with mass and diversity.

6.4 In our professional judgement, an uplift to CAPM was required, and we therefore applied a discount rate of 25 per cent in valuing Weight's database. We then used the same discount rate to arrive at our terminal value.

\section{VALUATION OF THE DATABASE}

7.1 A discount rate of 25 per cent applied to the forecast cash flows for the period to 31st December, 2009 implied a value for those cash flows at 31st December, 2004 of $\mathcal{E} 1,508,000$.

7.2 The same discount rate applied to the 2009 cash flows into perpetuity and, assuming a growth of 3 per cent, implies a terminal value of £1,065,000.

7.3 The total value of the database based on the projected income stream was therefore $\mathcal{E}^{2}, 573,000$.

7.4 The data on which CAPM is calculated is, however, based on transactions involving tiny minority holdings of stocks and shares. It does not take into account the fact that we are valuing the total control of the database. We are, therefore, of the opinion that a control premium of 20 per cent was appropriate in this case. This gives a total value for the 


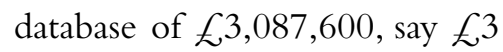
million.

7.5 A value of $\AA^{3}$ million implies a multiple of approximately 7.2 based on the projected 2005 operating profit. The average prospective Price/ Earnings ratio (' $\mathrm{P} / \mathrm{E}$ ') for the Media and Photography sector was at 18.5 at the time.

7.6 A prospective multiple of 18.5 requires a significant adjustment to reflect points of difference between those companies comprising the quoted sector and the Weight database. Such adjustments typically involve an uplift to reflect the fact we are valuing total ownership of the database and discounts to reflect the points we have already made in paragraph 6.3 above.

7.7 We also needed to adjust for tax in that our researched $\mathrm{P} / \mathrm{E}$ ratios are based on post-tax figures and here we were using pre-tax profits. In the circumstances, a multiple of $7.5 \mathrm{did}$ not look unreasonable to us.

\section{Cost to create}

7.8 Estimating the open market value of the database, using the cost approach, typically involves estimating either the reproduction cost or replacement cost of the asset. The reproduction cost equals the cost of constructing an exact replica of the subject intangible asset, while the replacement cost is identified as the cost to recreate a property with an equivalent utility of the subject intangible asset.

7.9 The management of Weight Inc. informed us that they believe there would be little or no difference between reproduction and replacement cost.

7.10 We were given a breakdown of the inflation-adjusted costs to create the database that gave a total cost of

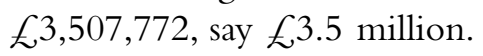

\section{VALUATION CONCLUSIONS}

8.1 We, therefore, had two values for the Weight database as at 31st December, 2004. The first utilising the income approaches gave a value of $f^{3}$ million and the second using cost created E3.5 million.

8.2 Both methods are considered to be appropriate for the valuation of a database, and therefore we believed an average of the two amounts would give us a suitable valuation.

8.3 We therefore valued the Weight database at $\_3.25$ million.

(C) Valuation Consulting Ltd 